Western University

Scholarship@Western

Department of Economics Research Reports

Economics Working Papers Archive

1980

\title{
The Effects of Alternative Urban Transit Subsidy Formulas
}

Mark W. Frankena

Follow this and additional works at: https://ir.lib.uwo.ca/economicsresrpt

Part of the Economics Commons

Citation of this paper:

Frankena, Mark W.. "The Effects of Alternative Urban Transit Subsidy Formulas." Department of Economics Research Reports, 8017. London, ON: Department of Economics, University of Western Ontario (1980). 
ISSN:

0318-725X

ISBN: $\quad 0-7714-0198-1$

\title{
RESEARCH REPORT 8017 \\ THE EFFECTS OF ALTERNATIVE URBAN \\ TRANSIT SUBSIDY FORMULAS
}

by

Mark W. Frankena*

\begin{abstract}
This paper demonstrates that for a given cost to the taxpayer, the effects of a transit subsidy depend on the subsidy formula, the objective function of the transit firm, and the transit demand function. Under most assumptions, a subsidy would lead to a lower fare, more service, and more riders, but under some assumptions the fare would remain unchanged or increase. If a transit firm maximlzes ridership, lump sum and ridership subsidies will have the same effects but a cost subsidy with the same cost to taxpayers will lead to a higher fare, more service, and lower ridership.
\end{abstract}


THE EFFECTS OF ALTERNATIVE URBAN TRANSIT SUBSIDY FORMULAS

Mark W. FRANKENA*

University of Western Ontario, Iondon, Ontario, Canada N6A 5C2

\section{Introduction}

The literature on urban transit subsidies analyzes the magnitude of the lump sum subsidy that would enable a transit firm to set service and fares at efficient levels. ${ }^{1}$ There is no systematic analysis of the effect of a subsidy on service, fares, and ridership if the objective of the firm is not efficiency and if the subsidy is not a lump sum. ${ }^{2}$ An understanding of these issues is important because there is an inciplent trend for transit firms to define their objectives in terms of ridership maximization rather than efficiency, ${ }^{3}$ and because many subsidies are based on transit expenditures rather than being lump sums.

This paper derives predictions about the effects of alternative transit subsidy formulas under various assumptions about the objective function of the transit firm. Under most of the circumstances considered, the model yields the intuitive prediction that transit subsidies would lead to a reduction in fares, an increase in vehicle miles of service, and an increase in ridership. However, under some assumptions, the model yields the counterintuitive prediction that a transit subsidy would not affect the fare or would lead to an Increase in the fare. The model also yields predictions about the comparative effects of different subsidy formulas. For example, if a transit firm maximizes ridership, lump sum and ridership subsidies will have the same effects but a cost subsidy with the same cost to taxpayers would lead to a higher fare, more service, and lower ridership. The predictions derived in this paper are amenable to econometric testing; some initial empirical results are presented in Frankena (1980a). 


\section{Aggregate Mode1 of an Urban Transit System}

Transit operations in a single city are described by a model which determines the aggregate city-wide levels of transit ridership and service and the fare. The model does not consider temporal or intraurban spatial variations in the fare, service, or demand for rides. The demand for rides is determined by the fare and the number of vehicle miles of service. The fare and number of vehicle miles are determined by a publicly-owned monopolistic transit firm, which maximizes an objective function subject to a budget constraint. ${ }^{4}$ The budget constraint requires that the transit firm's costs must equal its revenues, after allowing for subsidies. 5

\subsection{The Budget Constraint}

To derive a budget constraint for the transit firm, we make the following assumptions: (i) Total transit costs are proportional to vehicle miles of service. ${ }^{6}$ (ii) All transit revenues are derived from fares and subsidies. (iii) The fare per ride is uniform. (iv) The demand for rides is a decreasing function of the fare and an increasing function of vehicle miles of service. (v) The absolute value of the fare-elasticity of demand for rides is less than one at low fare levels, increases with the fare, and exceeds one at high fare levels. 8

Given these assumptions, in the absence of subsidies the transit system chooses a combination of the fare and vehicle miles of service which satisfies the following budget constraint:

$$
\mathbf{F R}-\mathbf{C M}=0
$$

where $F$ is the fare per ride, $M$ is the number of vehicle miles of transit service, $C$ is the cost per vehicle mile, and

$$
\mathbf{R}=\mathbf{R}(\boldsymbol{F}, \mathbf{M})
$$

is the demand function for rides. 9 
Substituting (2) into (1) gives a single equation in two unknowns, and hence a range of combinations of $F$ and $M$ will normally be consistent with the transit firm's budget constraint. Under reasonable assumptions, the relevant set of feasible combinations of $F$ and $M$ can be represented by a curve like $\mathrm{ZZ}^{\prime}$ (Figure 1), which we will refer to as the feasible

locus. ${ }^{10}$ In the absence of subsidies based on the number of passengers, the feasible locus slopes upward in the range of $F$ and $M$ for which the fare-elasticity of demand for rides $\left(E_{F}\right)$ is 1 less than one in absolute value and bends backward where $-E_{F}>1$.

\subsection{Objective Function}

The combination of $F$ and $M$ which the transit firm selects depends not only on the feasible locus but on the firm's objective function, which is assumed to take the form:

$$
\text { Maximize } U=U(F, M, R)
$$

where $U_{F} \leq 0, U_{M} \geq 0$, and $U_{R} \geq 0$ but $U_{M}$ and $U_{R}$ are not both zero. Cooter and Topakian (1980) provide a rationalization for including vehicle miles and ridership as arguments in the objective function on the grounds that transit managerial rewards may be based on these measures of the size of the enterprise, and it would be consistent with their discussion to rationalize inclusion of the fare as an argument in the objective function on the grounds that it is a determinant of electoral support.

Given the demand function (2), the objective function can be simplified:

$$
U(F, M, R)=U(F, M, R(F, M))=V(F, M)
$$

Thus, even if the firm cares about ridership as well as about the fare and vehicle miles, its objective function can be represented by indifference curves in which only $F$ and $M$ appear explicitly as arguments. 


\section{Figure 1}

Feasible Locus for Unsubsidized Firm and Indifference Curves for Three Alternative Objective Functions

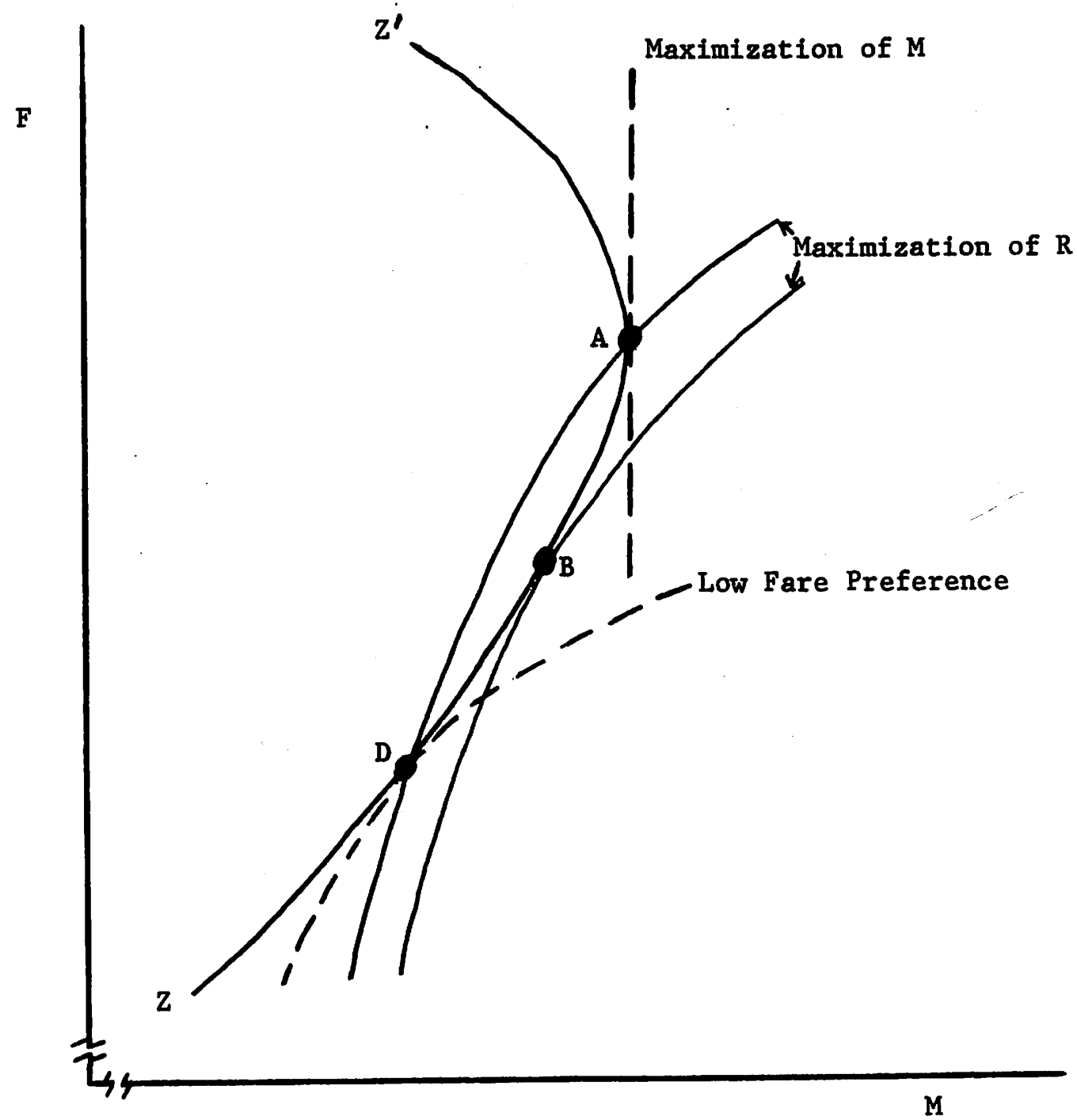


The indifference curves for three possible objective functions are depicted in Figure $1 .^{11}$ The indifference curves for a firm which maximizes vehicle miles are vertical lines, and the firm chooses the operating policy represented by point $A$ in Figure 1 (high fare, high vehicle miles, and low ridership). The indifference curves for a firm which maximizes ridership are "isorider curves", each of which gives the solutions to the equation $R(F, M)=R^{0}$ for a different value of $R^{0}$, and the firm chooses the operating policy represented by point B (medium fare, medium vehicle miles, and high ridership). It is important to note that maximum ridership occurs at a lower level of $F$ and $M$ than does maximum vehicle miles. The Indifference curves for a firm which is willing to cut service enough that ridership would decline in order to reduce the fare would have lower slopes than those corresponding to the objective of maximizing ridership. We will refer to such an objective as low fare preference. A firm with low fare preference chooses an operating policy such as the one represented by point D (low fare, low vehicle miles, and low ridership), southwest of point B.

\section{The Effect of Subsidies}

\subsection{Alternative Subsidy Formulas}

We will analyze three alternative transit subsidy formulas: (i) Iump sum subsidy--an exogenously determined amount of money which is not dependent upon the transit firm's operating performance. (ii) Cost subsidy--an exogenously determined fraction of costs. (iii) Passenger subsidy--an exogenously determined amount of money per passenger carried.

Given the assumption of constant cost per vehicle mile, a cost subsidy is identical to a service subsidy--an exogenously determined amount of money per vehicle mile. Also, in the absence of lump sum and passenger subsidies, 
given the budget constraint a revenue subsidy--an exogenously determined percentage of the transit firm's revenue--is identical to a cost subsidy at another rate. 12

In cases where two different levels of government provide subsidies to the same transit firm, it is common for one of the governments to provide a deficit subsidy--an exogenously determined percentage of the transit firm's deficit. Given the budget constraint of the transit firm, the effect of a deficit subsidy from one level of government is to provide a matching grant equal to some percentage of any subsidy provided by the other level of government. Consequently, the present model can be used to anslyze the combination of a deficit subsidy from one level of government and a lump sum, cost, or passenger subsidy from another level of government.

\subsection{Further Assumptions}

Two further assumptions must be made to use the model developed here to analyze the effects of subsidies. First, we assume that the subsidies analyzed would not change the cost per vehicle mile of transit service. Thus, we rule out the possibility that subsidies would lead to an increase in transit wages. Second, we assume that provision of government subsidies is not accompanied by government controls over transit operating policies or by organizational changes which would alter the transit firm's objective function.

\subsection{Effect of Subsidies on the Constraint}

Introduction of subsidies changes the transit firm's budget constraint from (1) to:

$$
\left(F+s_{3}\right) R+s_{1}-\left(1-S_{2}\right) G M=0
$$

where $s_{1}=$ lump sum subsidy; $s_{2}=$ fraction of costs covered by cost subsidy; and $s_{3}=$ passenger subsidy per ride. 
To determine how a subsidy would shift the feasible locus, one must make some additional assumptions about the demand function (2). For simplicity, in the figures we assume that, in the relevant range of values for $F$ and $M$, the fare-elasticity of demand $\left(E_{F}\right)$ is independent of $M$ and the elasticity of demand with respect to vehicle miles of service $\left(E_{M}\right)$ is independent of $F$. We also assume that $E_{M}$ declines as the level of $M$ increases. Some of the geometry and conclusions about the effects of subsidies would be different if we made different assumptions about these elasticities. This point will be 1 llustrated below.

Figure 2 shows the shapes of the feasible loci when there is no subsidy, when there is a lump sum subsidy, and when there is a cost subsidy. The subsidy rates have been selected so that the feasible loci for the cost and lump sum subsidies have one point in common, $G$, the fare and vehicle miles combination which maximizes vehicle miles. Apart from this common point, the feasible locus for the cost subsidy lies to the left of the feasible locus for the lump sum subsidy. This is because at point $G$ the total values of the two subsidies are equal. At. any lower level of $M$, the total value of the cost subsidy will be lower while the lump sum subsidy will be unchanged. Also, given our assumptions about the demand function, the maximum level of $M$ along the feasible loci for the lump sum and cost subsidies will occur along the horizontal line AGH. This follows from the fact that for either subsidy $M$ is maximized where total revenue and hence passenger revenue is maximized, $1 . e$, where $E_{F}=-1$, and by assumption $E_{F}$ is determined by the level of $\mathrm{F}$.

Figure 3 reproduces the feasible loci when there is no subsidy and when there is a lump sum subsidy from Figure 2 but also includes the feasible locus for a passenger subsidy. The subsidy rates have been selected so that the feasible loci for the passenger and lump sum subsidies have one point in common, $P$, the 


\section{Figure 2}

Feasible Loci for No Subsidy, Lump Sum Subsidy, and Cost Subsidy

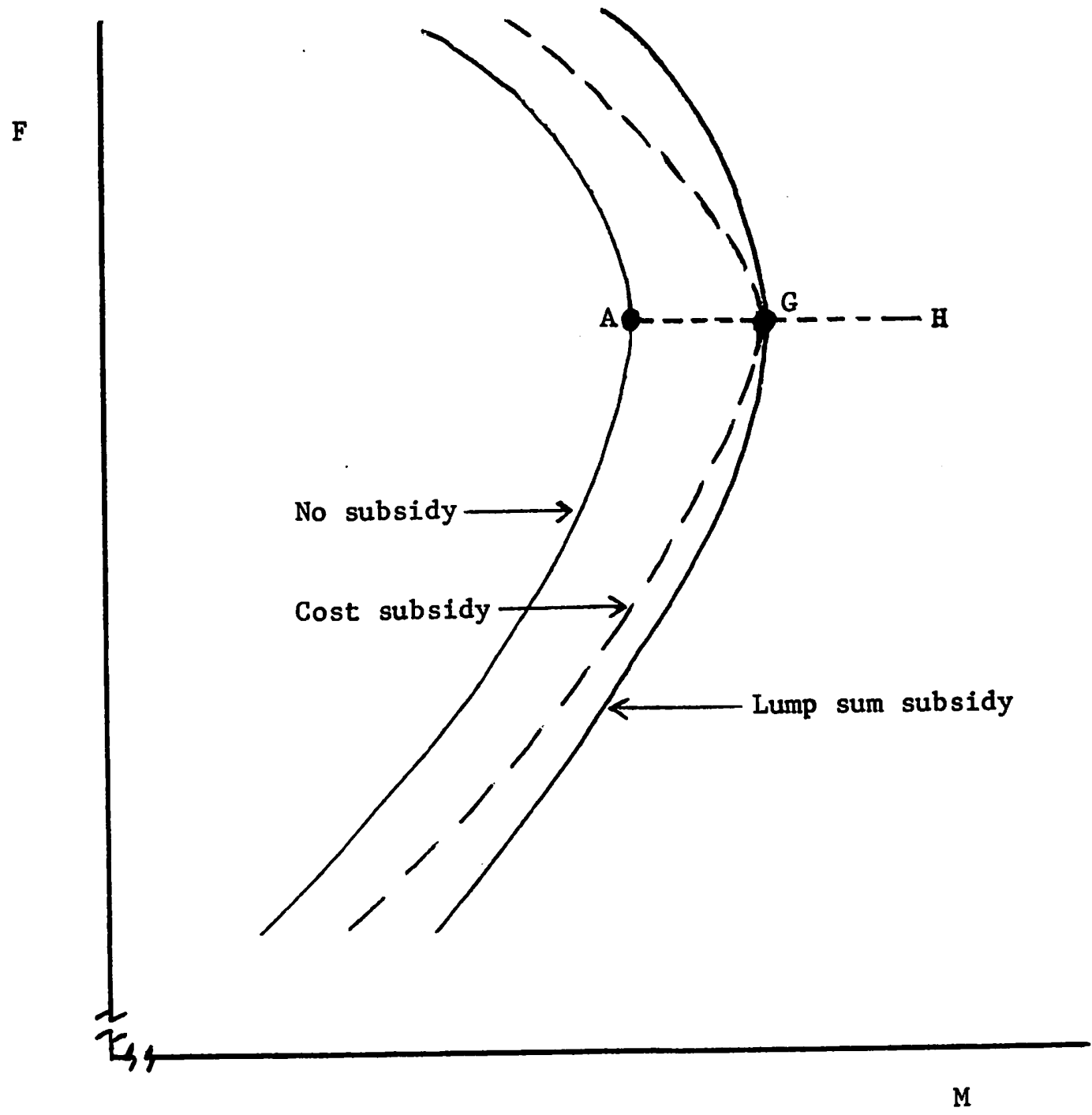




\section{Figure 3}

\section{Feasible Loci for No Subsidy, Lump Sum}

Subsidy, and Passenger Subsidy

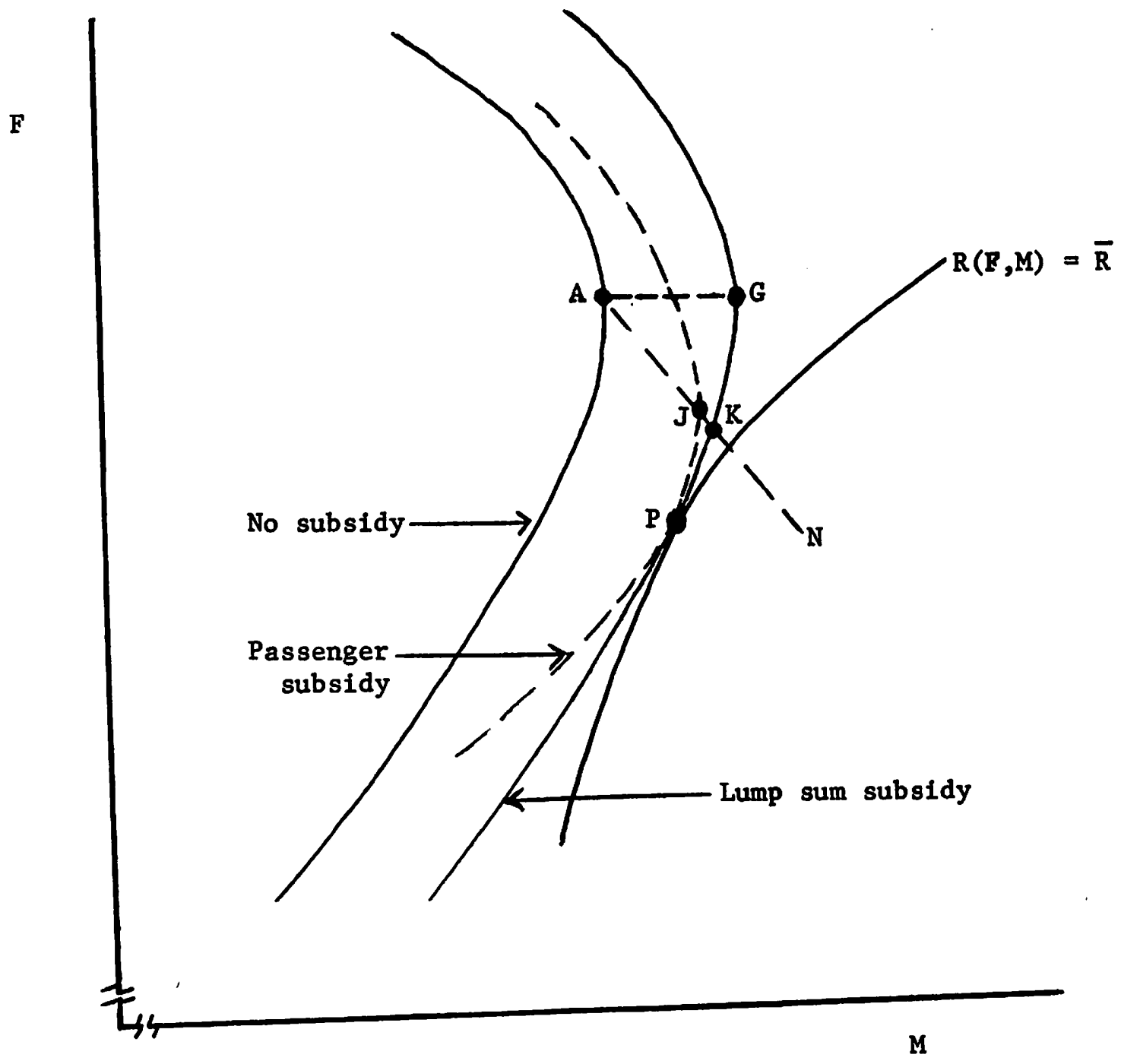


fare and vehicle miles combination which maximizes ridership. Apart from this common point, the feasible locus for the passenger subsidy lies to the left of the feasible locus for the lump sum subsidy. This is because at point $P$ the total values of the two subsidies are equal. At any other level of $M$, the level of $R$ and hence the total value of the passenger subsidy will be lower while the lump sum subsidy will be unchanged. Also, given our assumptions about the demand function, the maximum level of $M$ along the feasible locus for the passenger subsidy will occur at $J$, below the horizontal line AG. ${ }^{14}$

\subsection{Effects of Alternative Subsidies under Maximum Vehicle Miles Objective}

In this section we analyze the effects of the three subsidy formulas when the objective of the transit firm is to maximize vehicle miles of service.

\subsubsection{Lump Sum and Cost Subsidies}

From Figure 2 it is evident that under the assumptions which have been made about the demand function, a transit firm which maximizes vehicle miles of service would not change the fare and would simply increase service as much as possible in response to a lump sum or cost subsidy.

Suppose, however, that we make a different assumption about the demand function, namely that the absolute value of $\mathrm{E}_{\mathrm{F}}$ is a decreasing function of $\mathrm{M}$. In this case, a lump sum or cost subsidy which Increases $M$ would reduce the absolute value of $E_{F}$. In order to maximize vehicle miles of service, the transit firm would then raise $F$ until $E_{F}=-1$ again. If Figure 2 were redrawn to be consistent with this assumption about the demand function, the line AGH would slope up to the right. Since the assumption that the absolute value of $E_{F}$ is a decreasing function of $M$ cannot be ruled out a priori, the "counterintuitive" nature of the prediction that a lump sum or cost subsidy could lead to an increase in the fare 
is perhaps explained by the fact that transit firms are not expected to maximize vehicle miles of service.

By similar reasoning, it is easy to demonstrate that if the absolute value of $E_{F}$ is an increasing function of $M$, then a lump sum or cost subsidy would lead to a reduction in $F$ if the transit firm maximizes $M$.

In any event, regardless of these assumptions about the demand function, one can conclude that lump sum and cost subsidies which have the same cost to the taxpayer will have the same effects on $F, M$, and $R$ if the transit firm maximizes vehicle miles of service.

\subsubsection{Passenger Subsidy}

From Figure 3 we can see that if the transit firm maximizes vehicle miles of service a passenger subsidy will lead to a reduction in fare and an increase in vehicle miles of service along the path AJKN as the rate of subsidy is increased.

Thus we conclude that if the transit firm maximizes vehicle miles of service, a passenger subsidy will have a distinctly different effect on $F$ and $M$ than either a lump sum or a cost subsidy which has the same cost to taxpayers. In Figure 3, while a lump sum or cost subsidy would move the transit system to point G, a passenger subsidy with the same cost to taxpayers would move the transit system to point $K$. Both $F$ and $M$ would be lower, and $R$ would be higher, with the passenger subsidy than with the lump sum or cost subsidy.

\subsection{Effects of Alternative Subsidies under Maximum Ridership Objective}

\subsubsection{Lump Sum and Cost Subsidies}

Under the assumptions about demand which were made in constructing Figure 2, both a lump sum and a cost subsidy would increase $M$ without affecting $F$ if the transit firm maximizes vehicle miles of service. By contrast, lump sum and cost subsidies would not only increase $M$ but also reduce $F$ if the transit firm maximizes ridership. Thus, in Figure 4 a transit firm which maximizes ridership would operate at point B in the absence of subsidies. 
A cost subsidy would lead it to move along the line BTW and a lump sum subsidy would lead it to move along the line BXY.

As Figure 4 makes clear, the quantitative effects on $F$ and $M$ of lump sum and cost subsidies with the same cost to the taxpayer would differ if the transit firm maximizes ridership. Through any point where the feasible locus slopes up to the right, such as point $T$ in Figure 4 , the feasible locus corresponding to a cost subsidy would be flatter than the feasible locus corresponding to a lump sum subsidy, i.e., the opportunity cost to the transit firm of additional vehicle miles in terms of fare increases would be lower under a cost subsidy than under a lump sum subsidy. Consequently, if the transit firm maximizes ridership, a cost subsidy would lead to a larger increase in $M$ and a smaller reduction in $F$ than would a lump sum subsidy with the same cost to the taxpayer. In Figure 4, the cost subsidy would lead to an equilibrium at point $T$ while the lump sum subsidy would lead to an equilibrium at point $\mathrm{X}$, while both subsidy policies would have the same cost to taxpayers since $T$ and $X$ lie on the same lump sum subsidy locus.

It can also be concluded that if the transit system is maximizing $R$ then a lump sum subsidy would lead to a larger increase in $R$ than would the cost subsidy which has the same cost to taxpayers.

It should be added that the prediction that a cost subsidy would lead to a reduction in $\mathrm{F}$ if the transit firm maximizes ridership depends upon the assumption that $\mathrm{F}_{M}$ decreases as $M$ increases. If $\mathrm{E}_{M}$ is a constant and $E_{F}$ is independent of $M$, then a cost subsidy will have no effect on the fare. This follows from the equilibrium condition $-\mathrm{E}_{F}=\mathrm{E}_{M}$.

\subsubsection{Iump Sum and Passenger Subsidies}

Using Figure 3, it is evident that if a transit firm maximizes ridership then lump sum and passenger subsidies with the same cost to taxpayers will have the same effect on F, M, and $R$. This is because the feasible loci for the two subsidy programs would be tangent to the same "isorider curve" at the same combination of $F$ and $M$, as they are at point $P$. 


\section{Figure 4}

\section{Comparison of Lump Sum and Cost Subsidies}

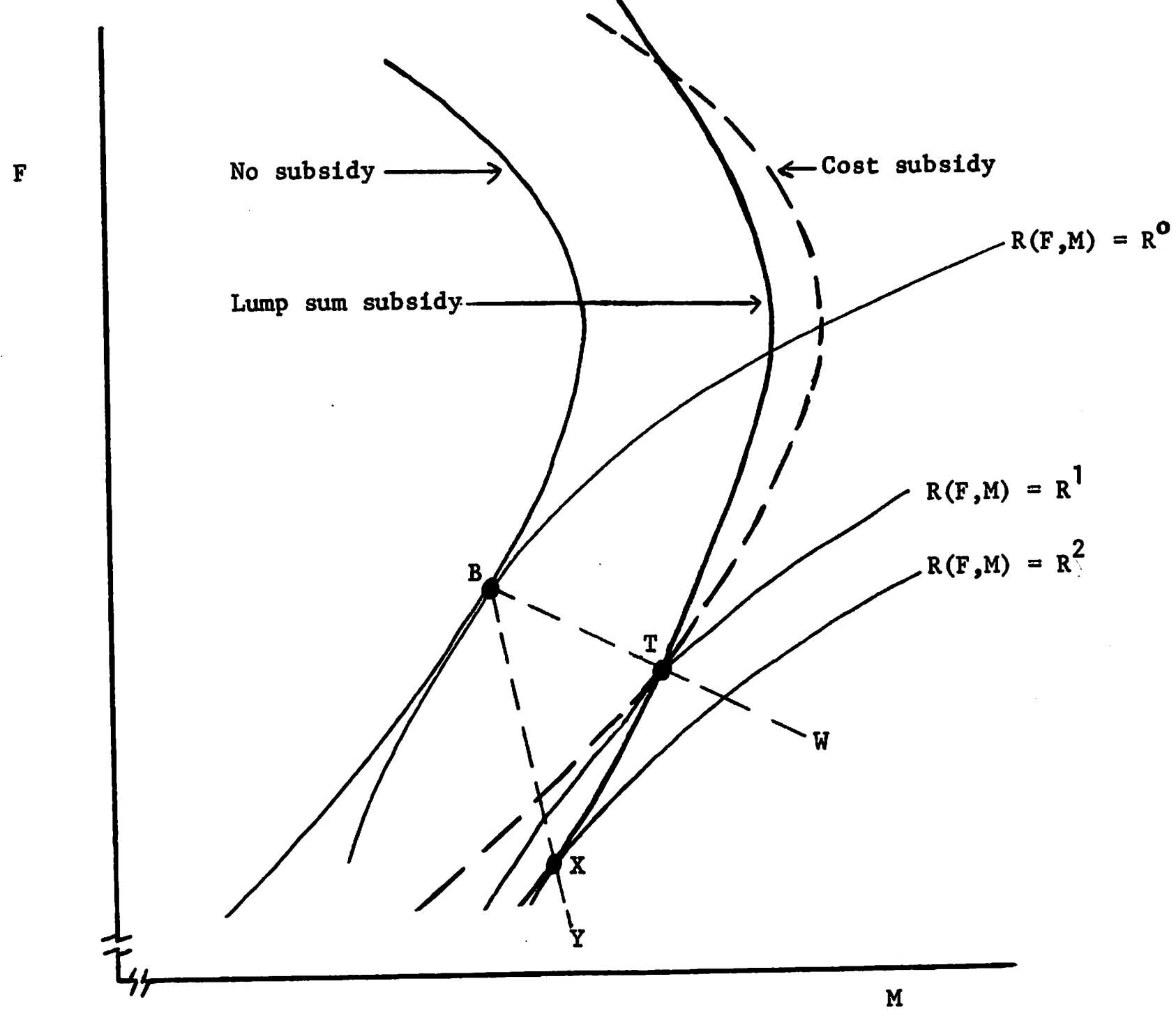


4. Summary and Implications for Empirical Rèsearch

The analysis in this paper has demonstrated that the qualitative as well as quantitative effects of a transit subsidy program with a given cost to taxpayers depend in important ways on the objective function of the transit firm, the subsidy formula, and the form of the demand function. These results should be of interest to government officials responsible for deciding on transit subsidy formulas, because there has been confusion over the differences among alternative formulas. Specifically, the analysis leads to the following conclusions :

(a) Under most of the alternative assumptions considered, the model ylelds the intuitive prediction that transit subsidies would lead to a reduction in fares, an increase in vehicle miles of service, and an increase in ridership.

(b) However, under some assumptions, the model ylelds the counterintuitive prediction that transit subsidies would not affect the fare or would lead to an increase in the fare. The model predicts that if the transit firm maximizes vehicle miles, lump sum and cost subsidies will lead to no change in the fare if the fare-elasticity of demand for rides is independent of the level of vehicle miles of service, and that they would lead to an increase in the fare if the absolute value of the fare-elasticity of demand is a decreasing function of the level of vehicle miles of service. The model also predicts that cost subsidies will lead to no change in the fare if the transit firm maximizes ridership, if the elasticity of demand for rides with respect to vehicle miles is constant, and if the fare-elasticity of demand for rides is independent of the level of vehicle miles.

(c) If the transit firm maximizes vehicle miles of service, lump sum and cost subsidies will have the same effects but a passenger subsidy with the same cost to taxpayers would lead to a lower fare, a lower level of vehicle miles, and a higher level of ridership than would lump sum or cost subsidies. 
(d) If the transit firm maximizes ridership, lump sum and ridership subsidies will have the same effects but a cost subsidy with the same cost to taxpayers would lead to a higher fare, more service, and lower ridership than would lump sum or cost subsidies.

(e) In addition to providing the preceding empirically testable predictions concerning the effects of transit subsidies, the analysis in this paper suggests a number of points that are relevant to the specification and testing of econometric models of urban transit. First, one should avoid imposing the assumption that the fare and vehicle-mile elasticities of demand are constants, because in the absence of subsidies any fare-elasticity other than minus one is inconsistent with maximization of vehicle miles of service and any fare-elasticity not equal in absolute value to the vehicle-mile elasticity is inconsistent with maximization of ridership. Second, inferences about the objective function of a transit firm can be made both by determining the location of the equilibrium relative to the points of maximum ridership and service along the feasible locus and also by testing the predictions concerning the effects of subsidies. 15 Third, because the fare, service, and ridership are determined simultaneously in the model, demand functions for urban transit rides should generally be estimated using simultaneous equation techniques. 


\section{Footnotes}

* The research reported in this paper was funded by the Ontario Economic Council. The author is indebted to Arthur J. Robson and two anonymous referees for suggestions.

${ }^{1}$ Some of the best work has been done in studies which analyze efficient fare policies, e.g., Mohring (1972) and Glaister and Lewis (1978).

${ }^{2}$ Preliminary simulation analyses comparing cost and ridership subsidies were carried out by Nelson (1972) and Peskin (1973).

3 The transit system in London, England, has announced that its objective is to maximize passenger miles, and a staff report prepared by the transit system in Toronto has recommended maximization of passenger trips as an objective. However, in practice the Iondon municipal council has refused to authorize fare increases required to maximize passenger miles. The objectives of ridership maximization and efficiency are compared by Nash (1978), Glaister and Collings (1978), and Frankena (1980b).

${ }^{4}$ One could argue that the transit system determines vehicle hours rather than miles of service. Vehicle miles would depend upon (i) vehicle hours, (ii) in-vehicle travel speed, which would depend on the level of automobile use and hence on transit fares and service, and (iii) vehicle loading time, which would depend on the level of transit ridership and hence on transit fares and service. Use of vehicle miles rather than hours of service ignores the impact of transit operating policies on congestion of roads and on congestion of the transit system itself. For an econometric model which uses vehicle hours, see Gaudry (1980).

${ }^{5}$ Similar models have been used by Nelson (1972), Nash (1978), and Frankena (1978). The model and its predictions could be adapted to nonurban public transport modes. 
${ }^{6}$ This assumption is consistent with empirical studies for bus firms by Lee and Steedman (1970) and Nelson (1972). The model would be more appropriate for rail systems if one assumed that total variable costs were proportional to vehicle miles of service and introduced fixed costs into the budget constraint. Assumption (1) excludes the possibillty of changing the cost per vehicle mile by changing the size of vehicles.

7 Exogenously determined non-fare revenues, such as investment income, could easily be introduced.

8 The absolute value of the fare-elasticity of demand is assumed to be less than one at low fare levels because empirical studies normally estimate it to be less than one at prevailing fare levels; the absolute value of the fareelasticity is assumed to rise above one at high fare levels so that the feasible levels of total transit revenue and vehicle miles of service have upper bounds.

9 Our use of the demand function assumes that there is no excess demand for transit rides; that is, vehicles are not too full to admit all people wishing to ride.

${ }^{1: 0}$ It is conceivable that there will be no feasible operating policy for which $M>0$. It is also conceivable that the feasible locus would be roughly circular. However, in the latter case the left half of the circle would consist of combinations of $F$ and $M$ at which the marginal revenue generated by an additional vehicle mile exceeds the marginal cost of an additional vehicle mile; these combinations of $F$ and $M$ would be dominated by those on the right half of the circle if the marginal utility of $M$ or $R$ in equation (3) is positive, and hence the left half of the feasible locus is ignored here. It follows that on the portion of the feasible locus illustrated in Figure $1, \mathrm{FR}_{\mathrm{M}}<\mathrm{C}$, or equivalently that the elasticity of demand for rides with respect to vehicle miles of service is less than one. Also, we assume that the positively sloped portion of the feasible locus in Figure 1 is strictly convex in the relevant range of values of $F$ and $M$. 
${ }^{1 I}$ We assume that $V(F, M)$ is quasi-concave. Quasi-concavity of $U(F, M, R)$ and concavity of $R(F, M)$ are sufficient for quasi-concavity of $V(F, M)$.

${ }^{12}$ In practice, a common transit subsidy formula is a capital cost subsidy-an exogenously determined percentage of the transit firm's capital costs. If the elasticity of substitution between capital and non-capital inputs were zero, this would be identical to a cost subsidy at some particular rate. However, if the elasticity of substitution is not zero, then a capital cost subsidy would lead to an increase in capital-intensity and an increase in the cost of transit service per vehicle mile. Analysis of this case would require introduction of a production function for transit service and is not pursued here.

${ }^{13}$ For evidence that subsidies do not lead to higher wages, see Frankena (1980b).

${ }^{14}$ Maximization of $M$ subject to (2) and (5) yields the condition $\left|E_{F}\right|=\left(1+s_{3} / F\right)^{-1}$, from which it follows that $\left|E_{F}\right|<1$ if $s_{3}>0$. Given our assumptions about demand, to reduce $\left|E_{F}\right|$ below $1, F$ marst be reduced below its level along AG.

${ }^{15}$ For example, the usual conclusion in empirical urban transit demand studies that $E_{M}>-E_{F}$ should not be interpreted as a universal property of transit demand at all combinations of $F$ and $M$. Rather, this finding suggests that transit firms have objective functions which are characterized by low fare preference. In the model presented in this paper, a transit firm which has a utility function characterized by $U_{F}=0$ would choose a combination of $F$ and $M$ at which $E_{M} \leq-E_{F}$, provided it obtained all its revenues from fares and cost subsidies. 


\section{References}

Cooter, R. and G. Topakian, 1980, Political economy of a public corporation: Pricing objectives of BART, Journal of Public Economics, for thcoming. Frankena, M., 1978, The demand for urban bus transit in Canada, Journal of Transport Economics and Policy 12, 280-303.

Frankena, M., 1980a, An econometric model of an urban transit system and the effects of subsidies, Department of Economics, University of Western Ontario, Iondon, Ontario.

Frankena, M., 1980b, Urban transportation financing in Ontario (Ontario Economic Council, Toronto, forthcoming).

Gaudry, M., 1980, A study of aggregate bi-modal urban travel supply, demand and network behavior using simultaneous equations with autoregressive residuals, Transportation Research B14, 29-58.

Glaister, S. and J. J. Collings, 1978, Maximization of passenger miles in theory and practice, Journal of Transport Economics and Policy 12, 304-321.

Glaister, S. and D. L. Lewis, 1978, An integrated fares policy for transport in London, Journal of Public Economics 9, 341-355.

Lee, N. and I. Steedman, 1970, Economies of scale in bus transport, Journal of Transport Economics and Policy 4, 15-28.

Mohring, H., 1972, Optimization and scale economies in urban bus transportation, American Economic Review 62, 571-604.

Nash, C. A., 1978, Management objectives, fares and service levels in bus transport, Journal of Transport Economics and Policy 12, 70-85.

Nelson, G. R., 1972, An econometric model of urban bus transit operations, Paper P-863, Institute for Defense Analyses, Arlington, Virginia.

Peskin, H. M., 1973, An analysis of urban mass transit subsidies, Paper P-793, Institute for Defense Analyses, Arlington, Virginia. 